\title{
The Research on the Psychological Motivation of the Encroach Behavior of the Ultimate Controlling Shareholder
}

\author{
Yongshen Chen \\ Business Administration, South China University of Technology, Guangzhou, China \\ Email: nicchen_cool@163.com
}

Received 6 November 2015; accepted 11 January 2016; published 14 January 2016

Copyright (c) 2016 by author and Scientific Research Publishing Inc. This work is licensed under the Creative Commons Attribution International License (CC BY). http://creativecommons.org/licenses/by/4.0/

(c) (i) Open Access

\section{Abstract}

Under the pyramid shareholding structure, the departure of the control right and the cash flow right of the ultimate controlling shareholder has enhanced the desire of the ultimate controlling shareholders of the listed companies to occupy, weighing the pros and cons, when the ultimate controlling shareholders think that the income of the encroach behavior is much more than the cost, he will encroach the listed company. The ultimate controlling shareholders' embezzlement infringes the interests of small and medium-sized shareholders seriously, at the same time, it brings serious negative effects on the long-term development of the listed companies, it even produces negative effect on the healthy development of capital market in China, so the study on the encroach behavior of the ultimate controlling shareholders is extremely essential. Based on the theory of psychological ownership, this paper conducts an in-depth study on the psychological motivation of the encroach behavior of the ultimate controlling shareholder. The study found that: under the pyramid shareholding structure, the control right of the ultimate controlling shareholder and the cash flow right depart, consequently, the control right of the ultimate controlling shareholders of the listed companies is greater than the cash flow right. The control right will influence the individual's psychological ownership right by three ways of information, assets and influence, and the ultimate controlling shareholder himself will produce psychological ownership via efficiency, self-recognition, having space and social exchange. The psychological ownership will lead to the expected earnings of ultimate controlling shareholders in the psychological level, but the real return of the ultimate controlling shareholder is determined by the cash flow right aka the corresponding proportion of share bonus, in the case of the separation of two rights, the expected income and actual income of the ultimate controlling shareholder will be misplaced, in order to compensate the income gap, the ultimate controlling shareholder will take encroach behavior to get more profit.

\section{Keywords}

The Separation of Two Rights, The Ultimate Controlling Shareholder, Ownership of 


\section{Psychological, Motivation, Encroach Behavior}

\section{Introduction}

The listed companies are an important part of the capital market in our country, with the growing maturity of our capital market, there are more and more laws and regulations on the listed companies, such as the independent director system, the construction of internal control, the set-up of the audit committee under the board and so on, these measures improve the quality of the listed companies to a great extent, and enhance the competitiveness of the listed companies. The improvement of the regulatory environment in the capital markets failed to prevent the big shareholders from occupying by related party transactions, cash holdings and illegally occupation of the funds of the listed companies and the soul of dividend policy means, which are the primary means of big shareholders to implement encroach behavior. In the capital market of China, the occupation phenomenon is widespread, such as the interests convey between the listed companies of Wuliangye group, the tunnel behavior towards its listed companies of Sanlian group, the occupation of GeLinKeEr towards Kelon electrical, the occupation of Deron towards the Tunhe corp in Xinjiang and so forth, all these behaviors have brought serious negative impact on the healthy development of of the listed companies, which can even be devastating. Moreover, the embezzlement is a serious violation of the interests of small and medium-sized shareholders of the listed companies, also it produces serious threat to the healthy and rapid development of the capital market. The protection of the regulation measures for the small and medium-sized shareholders seems very limited in the Capital market. Especially the capital market in China, most of the listed companies have pyramid shareholding structure, with such equity structure, the ultimate controlling shareholders can get some protection, consequently, their occupation behavior becomes more hidden. Moreover, the control right and the cash flow right of the ultimate controlling shareholders of listed companies under the pyramid shareholding structure depart from each other, which inspires the ultimate controlling shareholders' encroach desire a lot. The research on the encroach behavior of large shareholders mainly focused on the way of the occupation of the big shareholders, the results of the occupation behavior and the governance of the encroach behavior and so forth, there are not so many researches on the causes of the encroach behavior of the big shareholders, especially when it comes to the psychological motivation of the large shareholders. This paper argues that the psychological motivation is the starting point of the embezzlement, if we can understand the mechanism of the encroach motivation, and we tackle the behavior at the starting point, so the big shareholders' embezzlement can be stopped.

The big shareholders, especially under the pyramid shareholding structure, has actual control of the listed companies, however, the earnings of the ultimate controlling shareholders get from the listed company are not matched with their control right, it will inspire a kind of imbalance within the controlling shareholders, the imbalance results from the the dislocation of actual income and the expected income in the psychological level of controlling shareholders. Chu xiao-ping thinks that managers will produce psychological ownership in the exercise of control power, furthermore earning expectations will be produced, when managers' actual income and expected income differs, the managers may have encroach behavior [1]. As for the large shareholders, the actual income does not tally with the anticipated income, which has the same mechanism, under the pyramid shareholding control structure, the actual income of the ultimate controlling shareholder is decided by its cash flow right, and in the psychological level, his expected earning is greatly affected by the psychological ownership, the dislocation may lead to the big shareholders' embezzlement.

Psychological ownership is a concept created by the psychological ownership theory, this paper will conduct a further research on the psychological motivation of the encroach behavior of the ultimate controlling shareholders based on the theory of psychological ownership.

\section{The Control Right and the Cash Flow Right of the Ultimate Controlling Shareholders under the Pyramid Shareholding Structure}

The ultimate controlling shareholders can control the listed company by small cash flow right under the pyramid shareholding structure. The researchers found that many enterprises at home and abroad are under the control of pyramid equity. The research of LLS (1999) shows that about 26\% of the ultimate controlling shareholders tend 
to use the pyramid shareholding structure to facilitate control on the listed companies [2]. Claessen and other scholars (2000) conducted an in-depth study of 2980 companies, and they found that more than $30 \%$ of big companies are under the pyramid shareholding structure [3]. Also, most of the listed companies in china are under the pyramid shareholding structure. Under the pyramid shareholding structure, the listed companies are at end of the control chain, as shown in the figure is the most simple pyramid shareholding structure.

As shown in Figure 1, the equity proportion company $A$ has of company $B_{1}$ is $L_{1}$, the equity proportion the company $B_{1}$ has of the company $B_{2}$ is $L_{2}$, and so on, as for the company $B_{n-1}$, the equity proportion the company $B_{n-1}$ has of $B_{n}$ is $L_{n}$. We assume that $L_{i} \geq 51 \%(1 \leq I \leq n)$, so the former higher level company can control the next company at a low level. Easy to see, if the company $\mathrm{A}$ can control the company $\mathrm{B}_{1}$, the company $\mathrm{B}_{1}$ can control $B_{2}$, till the company $B_{n-1}$ can control the company $B_{n}$, as a result, the company $A$ can gain the control of the company $B_{n}$, we take company $A$ as the ultimate controlling shareholder of the company $B_{n}$. The company at the higher level can control the company at the lower level, whose control right is determined by its holding proportion in the company. As is shown in the figure, the control right of the ultimate controlling shareholders of company $B_{n}$ is determined by the minimum control right of the control chain. so the control right $\left(C_{1}\right)=$ MIN $\left(\mathrm{L}_{1} \mathrm{~L}_{2} \mathrm{~L}_{3} \cdots \mathrm{L}_{\mathrm{n}}\right)$.The cash flow right of the ultimate controlling shareholders is all the holding ratio time together, which is $\left(\mathrm{C}_{2}\right)=\Pi\left(\mathrm{L}_{1}, \mathrm{~L}_{2}, \mathrm{~L}_{3} \cdots \mathrm{L}_{\mathrm{n}}\right)$, which is the dividend percentage of the ultimate controlling shareholders from the listed companies at the end of the control chain. The control right, therefore, is the measurement of the size of the formal ownership of ultimate controlling shareholders of the listed companies, the cash flow right is the measurement of the profits of the ultimate controlling shareholders (UCS) from the listed companies.

If the holding proportion of every level is $100 \%, \mathrm{C}_{1}$ and $\mathrm{C}_{2}$ will not deviate from each other; If there is a $\mathrm{L}_{\mathrm{i}}$ $(1 \leq \mathrm{I} \leq \mathrm{n}) \leq 100 \%$, under this condition, there is deviation between $\mathrm{C}_{1}$ and $\mathrm{C}_{2}$, namely the control right and the cash flow right, consequently, the ultimate controlling shareholders may have occupation behavior [4]. The logical model is shown in Figure 2.

The Logical model above analyses the occupation behaviors at the reality level. UCS stands for the ultimate controlling shareholders. PSS stands for pyramid shareholding structure. while for the analysis of the ultimate controlling shareholders in inner psychological logic model, it requires the use of psychological ownership theory to help the analysis.

\section{The Psychological Ownership Theory}

\subsection{The Put-Forward of the Psychological Ownership Theory}

Jon L. Pierce was the first to put forward the concept of psychological ownership. In the 90s of the 20th century, Pierce had the view that it was a complicated process between the employee stock ownership plan and their attitudes or their behavior, and the psychological ownership worked as intermediary, he was the first to introduce the concept of psychological ownership [5]. Then, with more and more in-depth researches, psychological ownership has become a new academic concept. Etzioni has a unique point of view of ownership, he thinks that the ownership not only has a formal level but also it has a mental level [6]. So a lot of scholars began to treat ownership from the perspective of psychological direction, thinking the ownership as a psychological phenomenon, it is in such a situation that the concept of psychological ownership was raised.

\subsection{The Motivation and Dimensions of the Psychological Ownership}

Pierce presents three motives for the psychological ownership, the first one is the pursuit of efficiency (POE):

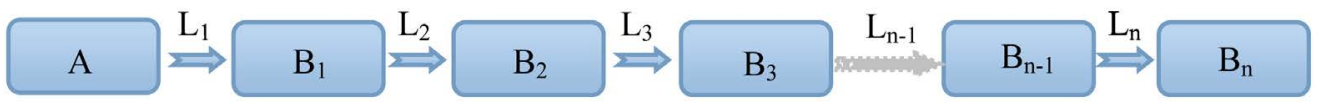

Figure 1. The simplest pyramid shareholding structure. Source: The summary of the author himself.

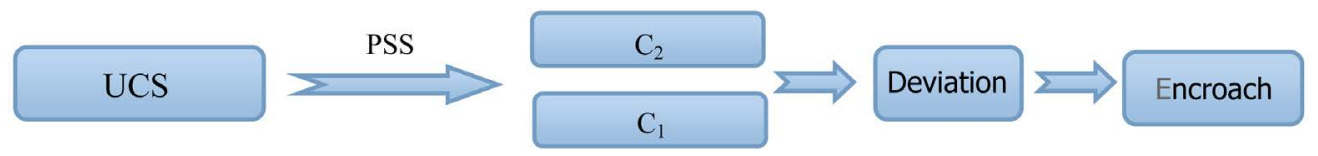

Figure 2. The logic of the ultimate shareholders' encroach behavior. Source: The summary of the author himself. 
this means that a person's desire to explore and change the environment. Secondly, the self-recognition (SR): it is the individual identification and definition of himself. The third one is occupied space (OS): this refers that the individual needs to have certain space and he tends to possess the space. Pierce thinks that if people have all the three motives, the psychological ownership will be produced [7]. Avery et al proposes that the psychological ownership has five dimensions which can be divided into two classes, namely promoting psychological ownership and defensive psychological ownership, the former has four dimensions: the sense of self-efficacy (SOS), self-identity, the sense of possession (SOP) and responsibility. The latter dimension is the sense of territory (SOT), which is a kind of psychological defense produced when an individual's possession of a target is under threats from outside [8]. Figure 3 shows the motives and dimensions of the psychological ownership.

\subsection{The Formation of Psychological Ownership}

Even if people had the three basic motives of the psychological ownership, they cannot directly lead to the emergence of the psychological ownership. As a matter of fact, the basic motivations play a role of promoting in psychological ownership's emergence, which needs ways to form. Pierce puts forward three possible ways of the psychological ownership's emergence: objectives control (OC), intimate understanding (IU), personal investment (PI), based on which, Avery puts forward the fourth forming path: social exchange (SE) [8]. Therefore, the paths to generate psychological ownership are the following four: objectives control, intimate understanding, personal investment, social exchange. In addition, the emergence of psychological ownership is also influenced by the target object's properties and the personal factors, environmental factors. Figure 4 shows the logic of psychological ownership's formation.

\section{The Analysis on the Ultimate Controlling Shareholders' Encroach Behavior}

When the manager's expected return and his actual income which is determined by its company system deviates from each other, the manager will conduct occupation behavior [1]. For the ultimate controlling shareholder, when his expected income differs from his actual income, the ultimate controlling shareholder's encroach behavior may happen.

Under the pyramid shareholding structure, the ultimate shareholder, as the ultimate controller of the listed company, first of all, has a strong will to control the operation of the listed company, and don't want other shareholders to operate the company .Additionally, the ultimate controlling shareholders has a real incentive to possess the listed company in order to seek for their largest shareholder' identity. Also, the ultimate controlling shareholder will assign his directors to work in the listed company, and he will invest a lot of manpower, material and financial resources into the listed company, as a result, the ultimate shareholder have more possession sense of the company. The ultimate controlling shareholder has the actual control of the listed company who

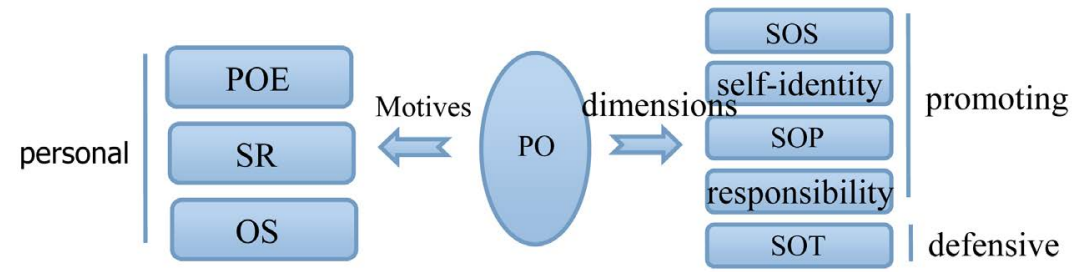

Figure 3. The motives and dimensions of psychological ownership (PO). Source: The summary of the author himself.

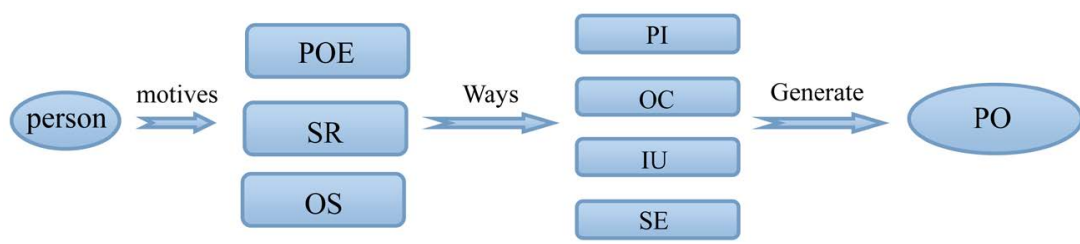

Figure 4. The path graph of personal psychological ownership's formation. Source: The summary of the author himself. 
possess the formal ownership, the formal ownership has great influence on the psychological ownership, which mainly enhances psychological ownership from three aspects: the possession of assets (PA), exerting influence (EI) and sharing information (SI). The three aspects are corresponding with the foregoing three paths [1]. What is shown in Figure 5 is the path graph about how formal ownership (FO) affects psychological ownership (PO).

Therefore, under the pyramid shareholding structure, from the psychological level, the ultimate controlling shareholder has the three kinds of motivation, and via the corresponding ways to produce psychological ownership, and his own formal ownership also strengthens the psychological ownership, which mainly manifests in the nature of the control. That is, the greater the ultimate controlling shareholder's control of the listed companies, the greater his psychological ownership is, and the greater psychological expected earning is.

The displacement of the ultimate controlling shareholders' expected income and the actual income is the main reason for the encroach behaviors. Psychological ownership has given rise to the ultimate controlling shareholders' psychological expectations of earning, therefore, Figure 6 shows the encroach behavior logic.

In the pyramid shareholding control structure, The control right of the ultimate controlling shareholder deviates from his cash flow right, the cash flow right means the proportion of bonus share that the ultimate controlling shareholder can get from the listed company, which determines the actual income (AI) of the controlling shareholder. The controlling shareholder has the motives and paths to produce psychological ownership, and his control right has further intensified their psychological ownership, thus leading to huge psychological ownership in the psychological level of the ultimate controlling shareholder. This huge psychological ownership will produce the corresponding expected income (EI) that the controlling shareholder should get from the listed company. When the ultimate shareholder's actual income and his expected return differs, the ultimate shareholder who is in control has the tendency to encroach.

Chu xiao-ping believes that only when the actual income of managers is lower than the expected returns, their occupation behavior occurs, what's more, the bigger the gap is, the stronger the motivation will be [1]. So, for the controlling shareholders, only when their actual earnings from the listed companies far below their expectations of revenues, the controlling shareholders will take encroach behavior.

Psychological ownership, as a kind of psychological feeling, often conflicts with the actual control right. The control right is determined by the shareholders' shares, when the proportion of shareholders has no change, their control is established. However, the influence factors of psychological ownership are various. In addition to the influence of the established formal ownership, the personal factors and environmental factors also have huge influence on psychological ownership, so the actual ownership and the psychological ownership can be a lot different. Because the controlling shareholders can control the operation of the listed companies, so once the ownership of psychological ownership dislocation is greater than the reality, the encroach behavior will occur.

\section{Summary and Suggestions}

\subsection{The Summary of the Encroach Behavior Analysis}

Based on the theory of psychological ownership, this paper deeply analyzes the psychological motivation of embezzlement of the ultimate controlling shareholders of the listed companies under the pyramid shareholding structure from the psychological level, by combining the separation between the control right and the cash flow right together with the mechanism of the formation of the psychological ownership of the ultimate controlling shareholders in the analysis, this article explain the encroach behavior of the ultimate controlling shareholders from a new perspective,. as shown in Figure 7.

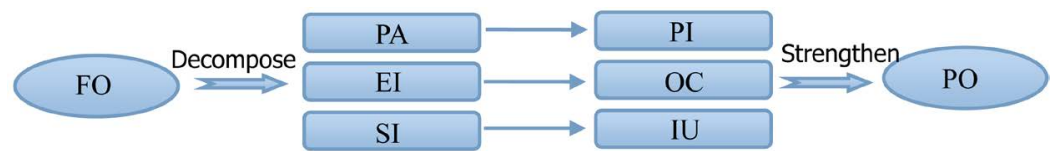

Figure 5. The path of how formal ownership effect psychological ownership. Source: The summary of the author himself.

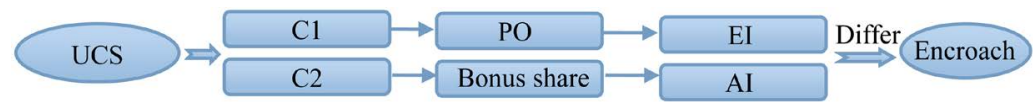

Figure 6. The logic of the ultimate controlling shareholders' encroach behavior. Source: The summary of the author himself. 


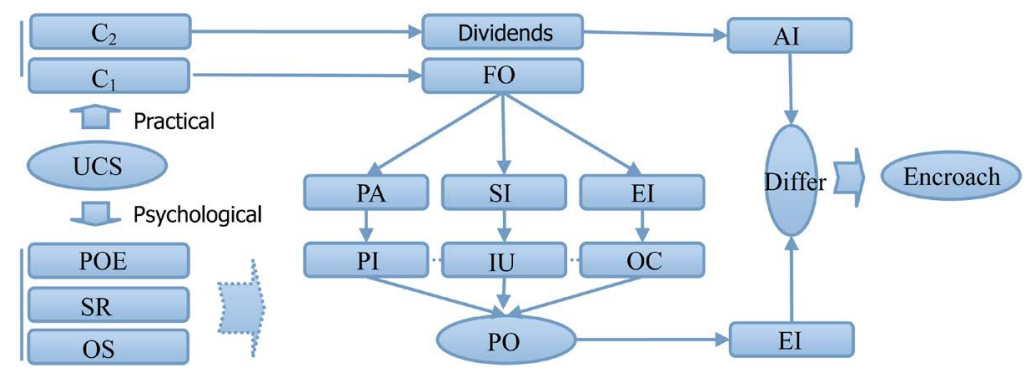

Figure 7. The analysis of the ultimate control shareholders' encroach behavior. Source: The summary of the author himself.

From the psychological level, the controlling shareholders have three motives, namely the pursuit of efficiency, self-recognition, space-occupied, and through three ways namely the control target, intimate understanding and individual invest to generate psychological ownership at the psychological level, at the real level, the formal ownership strengthens the psychological ownership of the controlling shareholders by three paths, namely by having assets, sharing information and presenting influence, then, the psychological ownership produces the expected earnings. In real terms, the ultimate shareholders' control right and cash flow right departs from each other, as we know, the control right has enormous influence on the generation and development of psychological ownership, thus it affects the expected earning, while the cash flow right determines the dividend of the ultimate shareholders, and the dividend determine the actual income of the ultimate shareholder. The separation between the control right and the cash flow right will lead to the result that the real earning of ultimate shareholder is much less than his expected earning, which will lead to the emergence of embezzlement.

\subsection{Suggestions}

The encroach behavior of the ultimate controlling shareholders has badly hurt the interests of minority shareholders, causing a lot of obstacles to the healthy development of the listed companies, even affecting the healthy development of capital market in our country, so it is necessary to govern the encroach behavior of the ultimate controlling shareholders under the pyramid shareholding structure. According to the research conclusion, this paper puts forward the following suggestions: 1) Optimize the shareholding structure, we need to reduce the separation degree of the control right and the cash flow right. The separation leads to the dislocation of the expected income and the real income, leads to the ultimate controlling shareholders' encroach motivation. Therefore if we reduce the separation degree of two rights, we can make controlling shareholders' expected interests more proper. 2) To clear the controlling shareholders' responsibility boundaries. If the ultimate controlling shareholders of the listed companies have too much interference, this will only enhance the psychological ownership of the controlling shareholders, increasing their expected return from the listed company. 3) Increase the cost of the embezzlement. Even if the expected income and the actual income of the ultimate controlling shareholders exists dislocation, he may not implement encroach behavior, only when the income the occupation behavior brings is greater than the cost of the encroach behavior, the ultimate controlling shareholders would like to encroach. So the cost of embezzlement becomes a powerful contain measure for the embezzlement. We should raise the cost of the ultimate controlling shareholders' encroach behavior, making the encroach behavior unprofitable.

\section{References}

[1] Chu, X.-P. and Liu, Q.B. (2005) The Explanation of the Job Occupation Behavior of the Professional Manager Based on the Psychological Ownership Theory. Management World, 7, 83-93.

[2] La Porta, R., Lopez-de-Silanes, F. and Shleifer, A. (1999) Corporate Ownership around in the World. Journal of Finance, 2, 471-517. http://dx.doi.org/10.1111/0022-1082.00115

[3] Claessens, S., Djankov, S., Fan, J.P.H. and Lang, L.H.P. (2002) Disentangling the Incentive and Entrenchment Effects of Large Shareholding. Journal of Finance, 57, 2741-2771. http://dx.doi.org/10.1111/1540-6261.00511

[4] Chen, H. and Yang, L.-X. (2012) Pyramid Shareholding Structure, Equity Checks and Balances and the Ultimate Shareholders' Encroach. Investment Research, 3, 101-113. 
[5] Pierce, J.L., Rubenfel, S.A. and Morgan, S. (1991) Employee Ownership: A Conceptual Model of Process and Effects. Academy of Management Review, 16, 121-144.

[6] Etzioni, A. (1991) The Socio-Economics of Property. Journal of Social Behavior and Personality, 3, 275-286.

[7] Pierce, J.L., Kostova, T. and Dirks, K.T. (2001) Toward a Theory of Psychological Ownership in Organizations. Academy of Management Review, 26, 298-310.

[8] Avey, G., James, B. and Bruce, J.A. (2009) Psychological Ownership: Theoretical Extensions, Measurement and Relation to Work Outcomes. Journal of Organizational Behavior, 30, 173-191. http://dx.doi.org/10.1002/job.583 